\title{
Biochemical Studies on Carbohydrates
}

CCXIX. Total Synthesis of Lactosamine-octaacetate

By

\section{Takasi Okuyama}

(奥山隆)

From the Medico-chemical Institute, Tohoku University, Sendai; Director: Prof. H. Masamune

(Received for publication, June 8, 1958)

Yosizawa ${ }^{1)}$ synthesized $\mathrm{N}$-acetyllactosamine from lactose in 1950, and Kuhn and Kirschenlohr') improved the method. The present account deals with a device to totally synthesize the same disaccharide. Since we found that 1,2,3-triacetyl-4,6-benzylidene- $\alpha$-glucosamine $(\mathbf{I})$ is obtainable from $\mathrm{N}$-acetylglucosamine in good yield $(1,2,3$-Triacetyl-4,6-benzylidene- $\beta$ glucosamine (II) is yielded much less), it was employed as one of the materials. It was debenzylidenated by heating $\left(20\right.$ minutes; $\left.100^{\circ} \mathrm{C}\right)$ with $60 \%$ acetic acid, and 1,2,3-triacetyl- $\alpha$-glucosamine (III) given was changed into 1,2,3,6-tetraacetyl- $\alpha$-glucosamine $(\mathbf{V})$ by controlled acetylation according to Levene and others ${ }^{3}$ and condensed with acetobromogalactose in the manner which Reynolds and Evans ${ }^{4}$ applied for preparing gentiobioseoctaacetate from 1,2,3,4-tetraacetyl-glucose and acetobromoglucose. The product (VI) (needles) melted at $224^{\circ} \mathrm{C}$ and had an $[\alpha]_{\mathrm{D}}$ (chloroform) value of $+57.7^{\circ}$. No depression of melting point occurred when it was heated with the octaacetate derived from natural $\mathrm{N}$-acetyllactosamine. And its O-deacetylation product gave a golden yellow spot with $\mathrm{R}_{\text {lactose }}$ of 1.34 as the $\mathrm{N}$-acetyllactosamine did, when paper-chromatographed with solvent butanol-pyridine-water $(5: 3: 2)$ and sprayed with the benzidine reagent of Raymonds and Morgan ${ }^{5)}$. Thus it was identified with the compound in view, although its condensation was very inefficient, yielding only $4 \%$ of theory, probably due to steric hindrance.

\section{EXPERIMENTAL}

1,2,3-Triacetyl-4,6-benzylidene- $\alpha$-glucosamine (I) and 1,2,3-triacetyl-4,6-benzylidene- $\beta$-glucosamine (II). $25 \mathrm{~g}$. of $\mathrm{N}$-acetyl-4,6-benzylidene-glucosamine ${ }^{6}$ ) was dissolved in a mixture of $100 \mathrm{cc}$. of dry pyridine and $40 \mathrm{cc}$. of acetic anhydride and stood in a refrigerator $\left(0--5^{\circ} \mathrm{C}\right)$ for 48 hours, the mixture was then poured into $1 l$. of iced water, and the white precipitate was washed with water and dried. It was extracted with two $100 \mathrm{cc}$. portions of chloroform, and the solutions were distilled to dryness and recrystallized from abs. ethanol twice. $25.5 \mathrm{~g}$. 


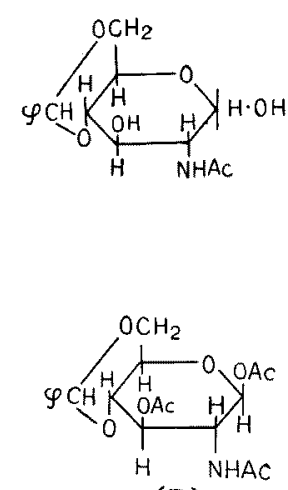

(II)

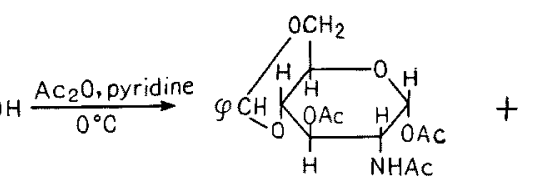

( I)

$60 \% \mathrm{ACOH}$. $100^{\circ} \mathrm{C}$

$\mathrm{HOCH}_{2}$

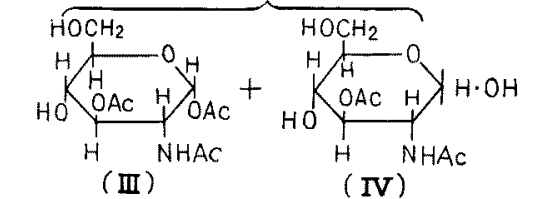

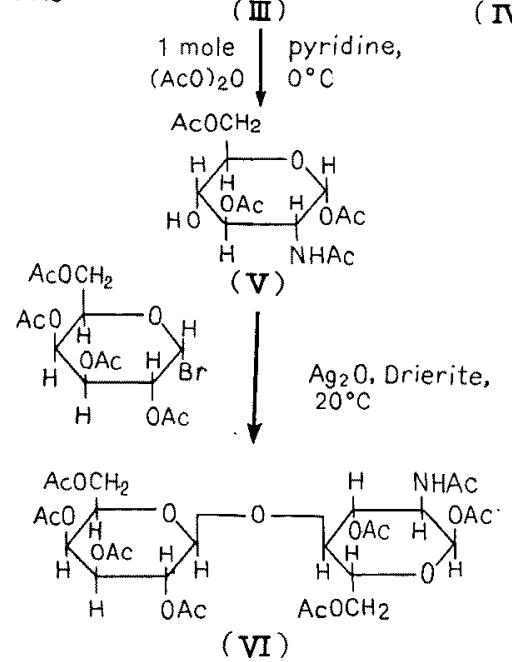

( $80 \%$ of theory) of fine needles was yielded. F.P. $200.5-201.5^{\circ}$ (decomp.). $[\alpha]_{\mathrm{D}}^{18}$ (pyridine) $=-100.9^{\circ}$ (c 0.7). Fehling positive. Soluble in chloroform, pyridine and methanol; slightly soluble in ethanol; insoluble in ether and water. Found: $\mathrm{N} 3.4 ; \mathrm{CH}_{3} \mathrm{CO}$, 31.7. $\mathrm{C}_{19} \mathrm{H}_{23} \mathrm{O}_{8} \mathrm{~N}$ requires $\mathrm{N}$, 3.6; $\mathrm{CH}_{3} \mathrm{CO}$, 32.8. As compared with the one below regarding optical rotation, this product is judged as the derivative of $\alpha$-glucosamine.

The chloroform-insoluble residue above was recrystallized twice from hot abs. methanol. About $2 \mathrm{~g}$. (6.3\% of theory) of soft long needles was yieldedthe derivative of $\beta$-glucosamine. F.P. $248-249^{\circ}$ (decomp.). [ $\left.\alpha\right]_{\mathrm{D}}^{\text {s }}$ (pyridine) $=-70^{\circ}$ (c 1.0). Found: N, 3.5; $\mathrm{CH}_{3} \mathrm{CO}, 32.5$. Fehling positive. Soluble in pyridine and hot methanol and ethanol; slightly soluble in chloroform and cold methanol and ethanol; insoluble in ether and water.

1,2,3-Triacetyl- $\alpha$-glucosamine (III). Hydrolysis of I with $60 \%$ acetic acid was found preferable to catalytic hydrogenation of it with Pd-black.

a) Catalytic hydrogenation. $7 \mathrm{~g}$. of 1,2,3-triacetyl-4,6-benzylidene- $\alpha$ glucosamine was taken up in a mixture of $50 \mathrm{cc}$. of dioxane and $150 \mathrm{cc}$. of abs. 
ethanol, $3.5 \mathrm{~g}$. of Pd-black was added, and the whole mixture was shaken with hydrogen gas at room temperature. When no more hydrogen was absorbed after 24 hours (The hydrogen gas consumed, $840 \mathrm{cc}$.), it was brought onto a suction funnel, and the filtrate was distilled. The dry still-residue was extracted with two $50 \mathrm{cc}$. portions of chloroform, and the solutions were washed with three $100 \mathrm{cc}$. portions of water. The chloroform-insoluble residue was dissolved in the washings of the chloroformic solutions and distilled to dryness. The glassy yellowish residue $(1.5 \mathrm{~g}$.) was recrystallized twice from abs. ethanol by addition of ether. $0.6 \mathrm{~g}$. ( $11.2 \%$ of theory) of crystals in the needle form was yielded. F.P. $142^{\circ} . \quad[\alpha]_{D}^{15}$ (abs. ethanol) $=+123^{\circ}$ (c 1.0). Fehling positive. Soluble in ethanol, water and hot chloroform; insoluble in ether. It gave a spot with $\mathrm{R}_{\mathrm{N} \text {-acetylglucosamine }} 2.8$, when paper-chromatographed (descending) with solvent butanol-ethanol-water $\left(5: 1: 4\right.$, upper layer; $\left.20^{\circ} \mathrm{C}\right)$. Found : N, 4.8; $\mathrm{CH}_{3} \mathrm{CO}$, $41.7 ; \mathrm{OH}, 11.78 . \mathrm{C}_{12} \mathrm{H}_{19} \mathrm{O}_{8} \mathrm{~N}$ requires $\mathrm{N}, 4.6 ; \mathrm{CH}_{3} \mathrm{CO}, 42.3 ; \mathrm{OH}, 11.15$.

b) Hydrolysis by the aid of $60 \%$ acetic acid. $19 \mathrm{~g}$. of 1,2,3-triacetyl-4,6benzylidene- $\alpha$-glucosamine was suspended in $200 \mathrm{cc}$. of $60 \%$ acetic acid and refluxed on boiling water, and the clear solution given in 7-10 minutes was heated further on for 20 minutes. When cold, the hydrolysate was washed with two $100 \mathrm{cc}$. portions of petroleum ether and three $100 \mathrm{cc}$. portions of chloroform and distilled in vacuo. The syrupy still-residue (light brown; $15 \mathrm{~g}$.) was taken up in about 10 volumes of abs. ethanol, decolorized with charcoal and concentrated to a syrup. It was then dissolved in $50 \mathrm{cc}$. of abs. ethanol, and after addition of ether to slight cloudiness, placed in a refrigerator. The white crystalline deposit was separated. Yield $12 \mathrm{~g}$. It began to melt at $138^{\circ}$ and melted

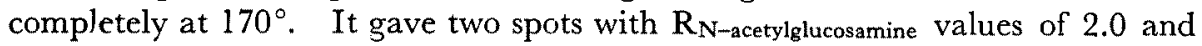
2.8 when chromatographed as above, suggesting the di- and tri-acetate. Hence it was dried in an Abderhalden apparatus $\left(\mathrm{P}_{2} \mathrm{O}_{5}, 56.5^{\circ} \mathrm{C}\right)$ and extracted continuously with chloroform in a Soxhlet apparatus for 48 hours. The solution was distilled, and the crystalline still-residue was recrystallized twice from abs. ethanol. $8.7 \mathrm{~g}$. ( $60 \%$ of theory) of needles was given. F.P. $142^{\circ} \cdot[\alpha]_{\mathrm{D}}^{\mathrm{s}}$ (abs. ethanol) $=+125^{\circ}$ (c 1.0). The product gave a spot at a position corresponding to the triacetate in a chromatogram developed as above, and the mixed melting point showed no depression.

2,3-Diacetyl-glucosamine (IV). The chloroform insoluble residue above $(5 \mathrm{~g}$.) was recrystallized from $50 \mathrm{cc}$. of a mixture of chloroform and methanol $(3: 1)$ three times. $3.6 \mathrm{~g} .(30.6 \%$ of theory) of long needles was obtained. F.P. $173-174^{\circ}$. It mutarotates D-light. [a $]_{\mathrm{D}}^{25}$ (abs. ethanol $)=+32.3^{\circ}$ (5 min.) $\rightarrow+21.0^{\circ}$ (45 min.) (c 1.3). Fehling positive. Soluble in water,

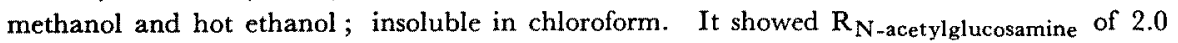
in a chromatogram developed as above. Found : N, 5.5; $\mathrm{CH}_{3} \mathrm{CO}, 31.5 ; \mathrm{OH}, 18.8 . \mathrm{C}_{10^{-}}$ $\mathrm{H}_{17} \mathrm{O}_{7} \mathrm{~N}$ requires $\mathrm{N}, 5.3 ; \mathrm{CH}_{8} \mathrm{CO}, 32.7 ; \mathrm{OH}, 19.4$.

The same diacetate was given in a yield of $92 \%$, when 1,2,3-triacetyl-4,6-benzylidene- $\beta$ glucosamine was treated as above. Namely, here almost all the material lost one acetyl besides the benzylidene.

1,2,3,6-Tetraacet $\nu l-\alpha$-glucosamine (V). $5 \mathrm{~g}$. of 1,2,3-triacetyl- $\alpha$-glucosamine was weighed in the $50 \mathrm{cc}$. brown flask (a) in Fig. 1, dissolved in $25 \mathrm{cc}$. of dry pyridine and chilled with ice. The solution was vigorously stirred, and $18.5 \mathrm{cc}$. 


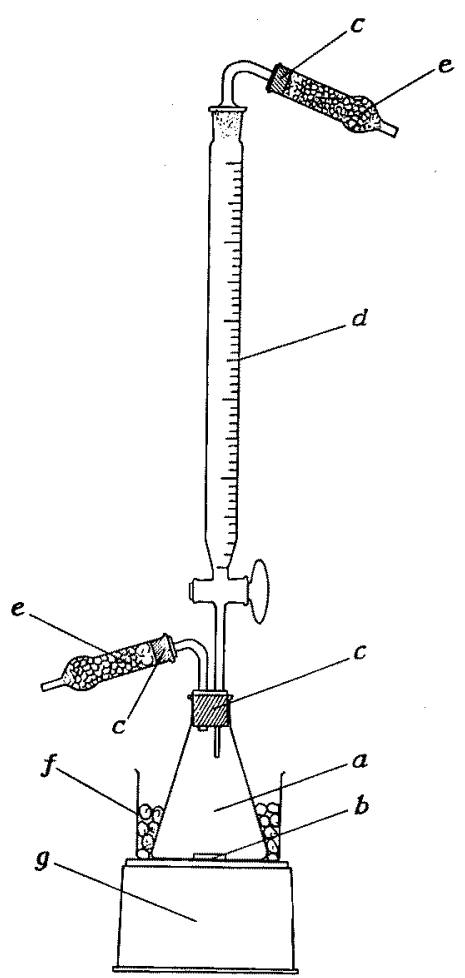

Fig. 1. Apparatus for controlled acetylation. $a: 50 \mathrm{cc}$. brown flask. $b$ : stirrer, $c$ : cork stopper, $d: 50$ cc. burette. $e: \mathrm{CaCl}_{2}$ granules. $f:$ ice pieces. $g:$ rotatory electric magnet.

of a $10 \%(\mathrm{w} / \mathrm{v})$ acetic anhydride solution in chloroform was added in drops during 1 hour. The mixture was stirred for another 1 hour under continuous cooling and then stood at room temperature for 12 hours. Followingly, it was poured into $100 \mathrm{cc}$. of iced water, and after standing for several hours, concentrated to a thin syrup (about $40 \mathrm{cc}$.). The condensate was distilled with toluene in vacuo repeatedly, until it smelled no more of pyridine. The final dry residue was taken up in $50 \mathrm{cc}$. of water and extracted with $50 \mathrm{cc}$. of chloroform 6 times in a separatory funnel. The combined chloroformic solutions were distilled to about $50 \mathrm{cc}$. under reduced pressure and extracted with an equal volume of water many times (10 times). The watery solutions were united, condensed to a glassy solid. Yield $3.5 \mathrm{~g}$. The product here gave two

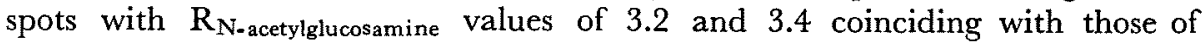
$1,2,3,6$-tetraacetyl- $\alpha$-glucosamine and of pentaacetyl- $\alpha$-glucosamine in a paper chromatogram developed as above. Therefore, it was dissolved in $15 \mathrm{cc}$. of hot abs. ethanol and placed in the refrigerator for 5 days. The crystalline deposit (long needles), which was the pentaacetate, was eliminated, ether was added to the mother fluid to faint turbidity, and this mixture was placed in the refrigerator 
for 1 week, whereby a small precipitate appeared. The supernatant fluid was decanted and concentrated by vacuum distillation. The hygroscopic stillresidue amounted to $2.5 \mathrm{~g}$. (45\% of theory). $[\alpha]_{\mathrm{D}}^{\mathrm{s}}$ (abs. ethanol) $=+87^{\circ}$ (c 1.01). Fehling positive. Found : $\mathrm{N}, 3.7 ; \mathrm{CH}_{3} \mathrm{CO}, 50.5 ; \mathrm{OH}, 4.0 . \mathrm{C}_{14} \mathrm{H}_{21^{-}}$ $\mathrm{O}_{9} \mathrm{~N}$ requires $\mathrm{N}, 4.0 ; \mathrm{CH}_{3} \mathrm{CO}, 49.6 ; \mathrm{OH}, 4.9$.

$\alpha$-Lactosamine-octaacetate (VI). A mixture of $2.5 \mathrm{~g}$. of 1,2,3,6-tetraacetyl$\alpha$-glucosamine, $2 \mathrm{~g}$. of silver oxide, $10 \mathrm{~g}$. of Drierite ${ }^{7)}$ and $25 \mathrm{cc}$. of chloroform was agitated in the $50 \mathrm{cc}$. brown flask (a) in Fig. 1 for 5 hours, and after addition of $0.4 \mathrm{~g}$. of iodine, $20 \mathrm{cc}$. of chloroform containing $3.2 \mathrm{~g}$. of acetobromogalactose was further added in drops during $l$ hour. The flask was taken off the apparatus, closed with a glass stopper (ground) and shaken for 5 days. The reaction mixture was filtered through charcoal, and the filtrate was washed with water thoroughly and distilled in vacuo to dryness. The still-residue was dissolved in $50 \mathrm{cc}$. of hot moist ether and placed in the refrigerator. The precipitate was recrystallized in a similar manner. $8 \mathrm{~g}$. of crystals thus given was taken up in $15 \mathrm{cc}$. of chloroform, petroleum ether was added to permanent cloudiness, and the mixture was also stood in the refrigerator. After 1 week, the crystals in needles were subjected to four repetitions of crystallization. The product weighed $0.18 \mathrm{~g}$. ( $4 \%$ of theory). F.P. $224-225^{\circ} . \quad[\alpha]_{\mathrm{D}}^{28}$ (chloroform) $=+57.7^{\circ}$ (c 1.07$)$. It melted at $223-225^{\circ}$ when mixed with the octaacetate derived according to Zilliken et al. ${ }^{81}$ from $\mathrm{N}$-acetyllactosamine which had been separated from the group mucopolysaccharide of pig stomach mucus after Masamune and Yosizawa.9) The product after deacetylation according to Kuhn et al. ${ }^{10)}$ showed a golden yellow spot with $\mathrm{R}_{\text {lactose }} 1.34$ in a descending chromatogram by solvent butanol-pyridine-water $(5: 3: 2)\left(20^{\circ} \mathrm{C}\right)$, when sprayed with the benzidine reagent of Raymonds and Morgan.5)

Through the Grant Committee for Scientific Researches the Ministry of Education gave a grant in aid to us, which is gratefully acknowledged. $\mathrm{H}$. Masamune.

\section{References and Notes}

1) Yosizawa, Tohoku J. Exp. Med., 1950, 52, 145.

2) Kuhn \& Kirschenlohr, Ann., 1957, 600, 135.

3) Raymond, Tipson \& Levene, J. Biol. Chem., 1939, $130,47$.

4) Reynolds \& Evans, J. Am. Chem. Soc., 1938, 60, 2559.

5) Raymonds \& Morgan, Naturwissenschaften, 1956, 178, 1171.

6) Masamune, Okuyama \& Sinohara, Tohoku J. Exp. Med., 1958, 68, 181.

7) Activated by heating at $240^{\circ} \mathrm{C}$ for 2 hours.

8) Zilliken, Smith, Rose \& György, J. Biol. Chem., 1954, 208, 299.

9) Masamune \& Yosizawa, Tohoku J. Exp. Med., 1956, 64, 267.

10) Kuhn, Baer \& Gauhe, Chem. Ber., 1955, 88, 1713. 